\title{
Using distance education in teaching orthotic fabrication to occupational therapy students
}

\author{
Husny Amerih ${ }^{1 *}$, Mohammad S. Nazzal $^{2}$, Hassan Elsalloukh ${ }^{3}$ \\ ${ }^{1}$ School of Occupational Therapy, Texas Woman's University, Denton, USA; ${ }^{2}$ Corresponding Author: Husny@twu.edu \\ ${ }^{2}$ Faculty of Applied Medical Sciences, Jordan University of Science \& Technology, Irbid, Jordan \\ ${ }^{3}$ Department of Mathematics and Statistics, University of Arkansas at Little Rock, Little Rock, USA
}

Received 1 March 2013; revised 10 April 2013; accepted 1 May 2013

Copyright (C) 2013 Husny Amerih et al. This is an open access article distributed under the Creative Commons Attribution License, which permits unrestricted use, distribution, and reproduction in any medium, provided the original work is properly cited.

\begin{abstract}
Occupational therapy (OT) education requires educators to provide students with entry level skills in orthotic fabrication. These skills have been taught in a traditional face-to-face classroom and labs. The concept of distance education (DE) has evolved over the years with the advancement of the technology. DE started with print media, radio broadcasting, and progressed to utilizing video conferencing. Currently DE relies heavily on using the internet to deliver quality, cost-effective and convenient education. DE Literature focused on teaching basic knowledge, however, no research was found that compared DE to traditional education in teaching skills or the application of knowledge. This pilot study investigated the effectiveness of using DE pedagogy in teaching OT students the skills of splint making, and to compare effectiveness of DE to that of traditional classroom. Forty OT students participated in the study, they self-selected to be in the experimental, or control group. The experimental group received training on splint making via the Blackboard ${ }^{\circledR}$, while the control group received similar training the traditional way. The quality of splints was evaluated; Mann-Whitney concluded that the difference between the means of the two groups was no significant, indicating that the quality of the splints were equivalent.
\end{abstract}

Keywords: Distance Education; Occupational Therapy; Teaching Skills; Splint Making;

Educational Pedagogy

\section{INTRODUCTION}

Occupational therapy (OT) is defined as "client-cen- tered health profession concerned with promoting health and wellbeing through occupation. The primary goal of occupational therapy is to enable people to practice in the activities of everyday life" [1]. OT is concerned with environmental, biological and psychological factors that inhibit occupational performance. Occupational therapists work with individuals whose abilities to cope with tasks of living are threatened by physical injuries, the aging process, psychological or social disability, chronic conditions, poverty, cultural differences, deficits in motor, sensory, cognitive, emotional or social development [2].

Current OT educational standards mandate training on entry level fabrication of custom-made splints and orthotics. Accreditation Council for Occupational Therapy Education (ACOTE) standard (B.5.11) states that entry level OT practitioners should have skill of "...selecting, designing, fabricating splints and/or modifying splints and orthotic devices..." [3].

A splint is defined as "an orthopedic device for immobilization, restraint, or support of any part of the body" [4]. Splints aim to mobilize, immobilize, position, or protect a specific joint/s or body part/s. Occupational therapist, among others professionals, are known for their splint-making skills. The task of making splints from raw materials is a highly complex task that requires knowledge of properties and handling characteristics of different thermoplastic materials, and knowledge of anatomy and kinesiology. Designing and fabricating custom-made splints requires problem solving, decision making, risk taking and skillful execution of the splint design [5]. Over the years the science and art of splint making have been taught by OT educators in the traditional face-to-face classroom and lab settings.

Traditionally, OT programs have taught splint making, and other hands-on skills, in classroom and lab settings. In these traditional face-to-face sessions the OT Instructor would provide step-by-step demonstration on splint making, or any other skills being taught, then students 
would be paired up to follow the step-by-step instructions in an attempt to produce a similar splint. The OT educator would move from station to station to provide feedback to students. The aim of this process is to equip students with the proper skills to produce orthotics, thus meeting one of the educational standards.

The dictionary defines skill as the ability to do something well, coming from one's knowledge, practice, aptitude, etc. [6]. Skills imply a know-how, expertise, dexterity and excellence in performing a given task. Teaching OT students the skills they need to become competent practitioners has been traditionally done in classrooms, lab sessions, hands-on training, simulation, clinical site visits, and fieldwork placement.

OT educators have been entrusted to teach their students an ever-changing set of skills to prepare them for competent OT practice. The skills needed for proper OT practice have transformed from the time of inception of OT in the early 1900 s, to our current time. Just a as people engage in an ever changing set of occupations, so does the focus of occupational therapy intervention. Weaving, block printing, stenciling, knotting, netting, basketry, pottery making, and woodwork used to be essential skills to OT practice [7], nowadays OT practitioners need to be familiar with, and skillful users of, ultrasound technology, electrotherapy stimulation, splint making, and administering group therapy sessions in mental health settings.

The technologies for transmitting knowledge and skills have evolved over the years as well. With the proliferation of technology, the provision of higher education looks totally different these days than it did just few years ago. Higher education of the twenty first century has moved away from University of Paris model, where the instructors were placed at the center of the academic process [8]. That model was effective in the Middle Ages up until few decades ago. Nowadays learning and teaching are not constrained by the dimensions of time and/or place anymore.

The concept of teaching and learning through using communication that is unbound by geography or time began in late 1800s using print media, through back and forth mailing. As technology advanced so did distance education (DE). DE started with print media, and progressed to using telephone conferences, radio and television broadcasting. DE was initially viewed as a radical and questionable way of teaching [9]. Currently DE is a respected and accepted way of learning; it is utilized because of its flexibility, mobility, affordability and portability. What started as a humble endeavor now has entire distance education and open university systems that utilize its principles. The United Kingdom's Open University educates 30,000 undergraduate and 15,000 post- graduate students utilizing principles of DE; it ranks fifth among UK universities for quality education whereas Oxford University is in sixth place [9].

Healthcare professions used distance education (DE) since the 1960s [10]. Videotaping patients for clinical training combined with live broadcasting to multiple sites was done in 1983 [11]. Nowadays DE is an umbrella term that refers to programs of study, or courses within a program, where educators are separated from learners by time and/or place [9]. Methods of delivering $\mathrm{DE}$ can be classified into three major categories; web-based technologies; pre-recorded media; or interactive videoconferencing. Any of these categories could be further classified into synchronous or asynchronous. If teaching occurs at the same time or at predetermined time, the DE will be classified as synchronous. If teaching time is flexible, DE will be called asynchronous [12].

Most research studies suggest that student achievement using DE is equal to traditional teaching methods [13]. Some studies concluded that even though students preferred the traditional face-to-face teaching, they performed significantly better on classroom content that was delivered via $\mathrm{DE}$ and that their overall performance was inversely correlated to grade point average [14]. Williams (2006) conducted a meta-analysis research on effectiveness of DE in allied health programs; she concluded that DE students had small positive gain in achievement when compared to traditional students. She also concluded that working professionals, who have some clinical experience, achieved significantly higher scores when compared to working professionals learning in traditional classroom. Students who chose DE over traditional education may be a characteristically different type of students. Successful DE learners tend to be introverted, intrinsically motivated, skillful time mangers, abstract thinkers [15]. To ensure success of all DE students, educators should begin with strong pedagogical foundation and use sound instructional design models that place the content and objectives before the choice of technology [12]. With the escalating use of DE to train graduate and undergraduate students, and working professionals, one should never lose focus of the quality of education.

Overwhelming majority of research studies that were reviewed for this project compared DE to traditional teaching methods focusing on classes that taught introductory concepts and basic knowledge, such as basic pathophysiology [14]. No literature was found that compared DE to traditional teaching for classes that focused on teaching skills or the application of knowledge. There is consensus among educators that healthcare students need to gain a deep understanding that goes beyond mere memorization and reproduction of facts. Research however, is lacking when it comes to testing the meaningful- 
ness and application of knowledge [9].

\section{Statement of Purpose and Relevance}

Most of research that was reviewed focused on students' acquisition of basic knowledge, understanding of new concepts or their satisfaction with DE. No research studies were found that focused on teaching or acquisition of new skills using DE pedagogy. This will be one of the first research projects that will evaluate the effectiveness of DE versus traditional education on students' acquisition of a skill. The implications of the findings will extend beyond teaching splinting to OT students. Findings will potentially impact how healthcare professionals in general are taught hands-on skills and how to apply knowledge to practice.

The purpose of this research was to investigate the effectiveness of using DE in teaching OT students the skills of splint making, and to compare DE effectiveness to that of traditional classroom/lab instructions. Specifically this research tried to answer the following questions: Do OT students who receive DE produce splints of the same quality as OT students who receive traditional splint making instructions?

\section{METHODOLOGY}

\subsection{Participants}

Participants were 40 OT students who were enrolled in OT5732: Specific Tools in Practice. One of the course objectives was to "demonstrate the ability to select and fabricate devices that meet the needs and goals of particular client...".

\subsection{Design}

OT Students learned how to fabricate three custommade hand splints during this course, among other class activities and objectives. The class met face-to-face to fabricate two splints. For the third splint students selfselected whether to attend the traditional classroom (control group-CG) or participate in the online group (experimental group-EG). The CG attended a demonstration session conducted by the instructor. The instructor demonstrated making a custom-made wrist extension splint, and then students were paired up and asked to fabricate similar splints. Students received training on splint making the traditional way; they received visual, verbal and hands-on instructions as they were fabricating the splint. The EG watched two on-line videos of the same instructor, making the same splint. The videos were step by step instruction that parallels the instructor's teaching in the traditional format. Videos were custom-captured and edited by the instructor who teaches the class, with help of two graduate students. Videos were posted on the Blackboard ${ }^{\circledR}$, and a Discussion Board was established to allow students to ask questions, if they have any. Upon arrival to the class, the EG students were asked to pair up and fabricate a splint like they've seen on the Blackboard ${ }^{\circledR}$.

\subsection{Data Collection}

Students in each group fabricate a custom-made splint and submitted it to the PI. The PI assigned random number to each splint. The splints were given to three independent and blind evaluators, who have received adequate training on grading the splints. Every evaluator scored each splints, and then the scores for each splint were averaged. The quality of splints was evaluated using the Splint Grading Form that accompanied the splinting textbook. The Splint Grading Form evaluates 14 different splint criteria, ranking each one on a scale of $1-5$, where $1=$ beyond improvement and $5=$ requires no improvement). The overall grade for each splint ranged from $14 / 70$ (poor quality) to 70/70 (excellent quality).

\section{RESULTS}

\subsection{Participants}

A total of forty OT students participated in the class, 14 self-selected to be in the control group, and 15 self-selected to be in the experimental group. Even with the clear instructions a groups of ten students ended up in both groups, they watched videos on $\mathrm{BB}$ and showed up for the instructor demonstration session, and one student did neither. After consulting with a statistician he recommended to discard the data for the latter two groups of students. Table 1 lists students in each group, and the quality of the splint they produced (see Table 1).

Table 1. A lists students in each group, and the quality of the splint they produced.

\begin{tabular}{cc}
\hline \multicolumn{2}{c}{ Quality of Splint (x/70) } \\
\hline Control Group & Experimental Group \\
\hline 56 & 47 \\
58 & 53 \\
45 & 49 \\
56 & 53 \\
57 & 54 \\
47 & 55 \\
57 & 49 \\
54 & 52 \\
52 & 54 \\
57.16 & 56 \\
56 & 54 \\
64 & 55 \\
53.83 & 54.66 \\
57.83 & 58.83 \\
& 60.66 \\
\hline
\end{tabular}


Table 2. Summary of statistics.

\begin{tabular}{|c|c|c|c|c|c|c|c|c|c|c|c|}
\hline Summary statistics: & $\mathrm{n}$ & Mean & Variance & Std. Dev. & Std. Err. & Median & Range & Min & $\operatorname{Max}$ & Q1 & Q3 \\
\hline Experimental Group & 15 & 53.67 & 12.682281 & 3.56 & 0.919503 & 54 & 13.66 & 47 & 60.66 & 52 & 55 \\
\hline Control Group & 14 & 55.05 & 22.230413 & 4.71 & 1.260114 & 56 & 19 & 45 & 64 & 53.83 & 57.16 \\
\hline \multicolumn{12}{|l|}{$\begin{array}{c}\text { H0: exper-cont }=0 \text { VS } \\
\text { H1: exper-cont } \neq 0\end{array}$} \\
\hline Difference & $\mathrm{n} 1$ & $\mathrm{n} 2$ & Diff. Est. & Test Stat & P-value & $95 \% \mathrm{CI}$ & & & & & \\
\hline Exper-cont & 15 & 14 & -2 & 195 & 0.196486 & $(-41.17)$ & & & & & \\
\hline
\end{tabular}

\subsection{Statistical Analysis}

Splint Quality data were analyzed using normality tests and plots to assess whether the distribution of the variables (experimental group and control group) fitted a normal distribution. Due to the small samples sizes and therefore non-normal distributions, the nonparametric, Mann-Whitney, test was used to assess whether the difference between the two variables (exper. Grp. and Cont. Grp.) medians were significant. All the analyses were performed using the Statistical Analysis Software $\left(\mathrm{SAS}^{\circledR}\right)$. The EG (mean 53.68, median 54) was not significantly different than the CG (mean 55.06, median 56), $(\mathrm{P}=0.1965)$ and $95 \% \mathrm{CI}=(-41.17)$, Table 2 .

\section{DISCUSSION}

Although distance education has been accepted medium of education for few decades, most research focused of acquisition of basic knowledge or satisfaction with the DE experience. Researcher found no research that focused on teaching skills utilizing DE pedagogy. This pilot study attempted to do that with a healthcare profession. The statistical analysis concluded that there were no significant differences between the means and medians of the control group and these of the experimental group. Which explicitly suggest that a new skill can be taught and acquired using online education.

These days, there is a widespread use of the internet to deliver continuing education units (CEUs) among healthcare professional, those CEUs are usually required for relicensing and to ensure up-to-date competencies. The findings of this pilot research suggest that the internet is as effective as face-to-face education in learning skills. This will be paramount importance among practitioners in rural areas and those in developing countries.

A sample size of forty students in one healthcare discipline makes hard to generalize the results to other health care professions. Future studies should include physical therapy, speech therapy, and nursing students. Also the self-selection of students may have biased the results one way or the other. Future studies should include larger sample size, and have strict randomization of groups.

\section{ACKNOWLEDGEMENTS}

The researchers thank TWU-OT students who agreed to participate in this research.

\section{REFERENCES}

[1] World Federation of Occupational Therapists (2010) Definition of occupational therapy from member organizations. www.wfot.org

[2] Johnson, J.A. (1974) Occupational therapy: A profession in transition. In: Hamburg, J., Ed., Review of Allied Health Education, The University Press of Kentucky, Lexington, 201-229.

[3] Accreditation Council for Occupational Therapy Education (2012) 2011 ACOTE standards and interpretive guide. http://aota.org/Educate/Accredit/Draft-Standards/50146.a spx?FT=.pdf

[4] Anderson, D.M., Keith, J., Novak, P.D. and Elliot, M.A. (2012) Mosby medical, nursing and allied health dictionary. 9th Edition, Elsevier, Mosby.

[5] Coppard, B. and Lohman, H. (2008) Introduction to splinting: A clinical reasoning and problem-solving approach. 3rd Edition, Mosby Elsevier, St. Louis.

[6] Merriam Webster Inc. (2001) The random house Webster's dictionary. 4th Edition, Ballantine Books, New York.

[7] American Occupational Therapy Association (1930) Minimum standards for courses of training in occupational therapy. AOTA, New York.

[8] Forest, J.J. and Kinser, K. (2002) Higher education in the United States, an Encyclopedia. ABC CLIO, Santa Barbara.

[9] Hollis, V. and Madill, H. (2006) Online learning: The potential for occupational therapy education. Occupational Therapy International, 13, 61-78. doi:10.1002/oti.209

[10] Williams, S. (2004) A meta-analysis of the effectiveness of distance education in allied health science programs. Ph.D. Diss., University of Cincinnati, Cincinnati.

[11] Davis, J. (2009) The power of video technology: creating effective teaching tools to enhance clinical reasoning and practice skills in occupational therapy curriculum. AOTA Annual Conference, Houston.

[12] Dudding, C. and Purcell-Robertson, R. (2003) Beyond 
the technology. ASHA Leader, 6, 6-7, 10, 16.

[13] Wright, V., Marsh, G. and Miller, M. (2000) Critical comparison of graduate student satisfaction in asynchronous and synchronous course instruction. Planning and Changing, 31, 107-118.

[14] Maring, J., Cosstello E. and Plack, M. (2008) Student's outcome in pathophysiology course based on mode of de- livery: Distance versus traditional classroom learning. Journal of Physical Therapy Education, 22, 24-32.

[15] Williams, S. (2006) The effectiveness of distance education in allied health science programs: A meta-analysis of outcomes. The American Journal of Distance Education, 20, 127-141. doi:10.1207/s15389286ajde2003_2 